\title{
Penampilan Agronomis dan Produktivitas Galur-Galur Padi Rawa di Lahan Lebak Bengkulu
}

\author{
Agronomic Performances and Productivity of Swamp Rice Lines on Swampy Land of Bengkulu
}

\author{
Sumardi", Mohammad Chozin, dan Sigit Sudjatmiko \\ Fakultas Pertanian, Universitas Bengkulu \\ Jl. WR. Supratman, Kandang Limun, Bengkulu 38371A, Indonesia
}

Diterima 14 Januari 2021/Disetujui 20 April 2021

\begin{abstract}
Swamp rice breeding program offers a strategic value in optimizing the function of swampy area as a source of food production by means of providing high yield and adaptive rice varieties in swamp ecosystems. The aim of this study was to evaluate the agronomic performances and productivity of ten swamp rice lines. The experiment was carried out from June 2018 to November 2018 on shallow swampy land, Faculty of Agriculture, Bengkulu University, using a complete randomized block design with three replications. The swamp rice lines were UBPR 1, UBPR 2, UBPR 3, UBPR 4, UBPR 6, UBPR 7, $U B P R$ 8, UBPR 9, UBPR 10, and UBPR 11 with Inpara 4 and Inpara 5 as the check varieties. The results showed that the 12 genotypes evaluated had significant variations in their agronomic performances and productivity. UBPR 4, UBPR 9, and $U B P R 11$ had similar agronomic performances and productivity compared to the check varieties. UBPR 2, UBPR 7, and $U B P R 8$ showed comparable agronomic performances to the two check varieties, but higher in productivity. UBPR $1, U B P R$ 3, UBPR 4, and UBPR 10 had relatively high plant stature and delayed maturity, but higher yield potential, than the check varieties. Further evaluation for adaptability and yield stability of the lines under different swamp typologies is required before release.
\end{abstract}

Keywords: Bengkulu local rice, grain yield, plant posture, swamp rice lines

\section{ABSTRAK}

Program pemuliaan padi rawa memiliki nilai strategis dalam upaya mengoptimalkan fungsi lahan rawa sebagai sumber pangan melalui penyediaan varietas-varietas padi berdaya hasil tinggi dan adaptif pada ekosistem rawa. Penelitian ini bertujuan untuk mengevaluasi penampilan agronomis dan produktivitas sepuluh galur padi rawa. Percobaan dilaksanakan mulai Juni 2018 hingga November 2018 pada lahan lebak dangkal Fakultas Pertanian Universitas Bengkulu berdasarkan rancangan acak kelompok lengkap dengan tiga ulangan. Galur padi rawa yang dievaluasi adalah UBPR 1, UBPR 2, UBPR 3, UBPR 4, UBPR 6, UBPR 7, UBPR 8, UBPR 9, UBPR 10, dan UBPR 11 dengan Inpara 4 dan Inpara 5 sebagai varietas pembanding. Hasil penelitian menunjukkan bahwa 12 genotipe yang evaluasi memiliki penampilan agronomis dan produktivitas yang beragam. UBPR 4, UBPR 9, dan UBPR 11 memiliki penampilan agronomis dan produktivitas yang setara dengan kedua varietas pembanding. UBPR 2, UBPR 7, dan UBPR 8 memiliki penampilan agronomis yang setara dengan kedua varietas pembanding, namun produktivitasnya lebih tinggi. UBPR 1, UBPR 3, UBPR 4, dan UBPR 10 memiliki postur tanaman yang relatif tinggi dan umur lebih dalam dibandingkan dengan dua varietas pembanding, namun produktivitasnya lebih tinggi. Pengujian lanjutan pada berbagai tipologi rawa masih diperlukan untuk mengevaluasi adaptabilitas dan stabilitas hasilnya sebelum galur-galur tersebut diusulkan untuk dilepas menjadi varietas unggul baru.

Kata kunci: galur padi rawa, hasil gabah, padi lokal Bengkulu, postur tanaman

\section{PENDAHULUAN}

Alih fungsi lahan sawah menjadi lahan non-pertanian merupakan fenomena yang terjadi pada hampir semua daerah dan sulit dihindari akibat pertumbuhan ekonomi dan

\footnotetext{
* Penulis untuk korespondensi. e-mail: sumardi@unib.ac.id
}

jumlah penduduk yang terus meningkat. Pada skala nasional, laju alih fungsi lahan sawah mencapai 96.512 ha per tahun dan jika fenomena tersebut terus berlanjut, maka pada tahun 2045 lahan sawah yang tersedia diperkirakan hanya tinggal 5.1 juta ha (Mulyani et al., 2016). Selama ini sebagian besar produksi padi nasional berasal dari lahan sawah, sehingga dengan berkurangnya luas lahan sawah akan memiliki dampak yang besar terhadap penyediaan pangan bagi 
masyarakat. Program pencetakan sawah baru merupakan upaya yang ditempuh untuk mengantisipasi ancaman krisis pangan, namun laju pencetakan sawah hanya berkisar antara 40,000-50,000 ha per tahun (Takim, 2018), atau lebih rendah dibanding laju alih fungsi lahan sawah. Karena itu, upaya-upaya lain masih perlu ditempuh guna mengimbangi defisit lahan sawah, termasuk pemanfaat lahan rawa yang ketersediaannya masih sangat luas.

Luas lahan rawa di Indonesia mencapai 33.40 hingga 34.93 juta hektar yang tersebar diberbagai pulau besar (Suriadikarta dan Sutriadi, 2007), antara lain Sumatera, Kalimantan, Papua, dan Sulawesi. Dari luas lahan rawa yang tersedia tersebut, 4.92 juta hektar telah dibudidayakan untuk tanaman padi dan sekitar 5.04 juta hektar sesuai untuk perluasan pengembangan tanaman padi (Djafar, 2019). Jika potensi sumberdaya alam tersebut dimanfaatkan secara optimal untuk produksi padi, maka lahan rawa akan menjadi agroekosistem yang dapat berkontribusi sangat besar terhadap peningkatan penyediaan pangan nasional di tengah pesatnya penyusutan lahan-lahan sawah akibat alih fungsi lahan.

Hambatan utama dalam mengoptimasi pemanfaatan lahan rawa untuk produksi padi terkait dengan dengan fisikokimia lahan. Secara fisik, pembatas utama dalam pemanfaatan lahan rawa memiliki rezim air yang fluktuatif dan sering mengakibatkan perendaman tanaman dengan kurun waktu yang sering cukup lama, baik karena karena curah hujan maupun pasang surut air laut (Sudana, 2017). Secara kimia, lahan rawa umumnya memiliki tingkat kesuburan rendah dan bereaksi masam (Waluyo dan Djamhari, 2011; Gazal dan Fathurrahman, 2019 ). Selain pembatas tersebut, keberadaan zat beracun, seperti Al, pirit, dan salinitas, merupakan pembatas tambahan pada lahan rawa pasang surut (Subagio, 2019; Hairmansis, 2020).

Budidaya padi pada lahan rawa secara tradisional telah lama dikenal dan dipraktikkan masyarakat dengan memanfaatkan varietas padi rawa lokal sekalipun produktivitasnya sangat rendah. Beberapa laporan menunjukkan bahwa rata-rata produktivitas padi rawa masih sangat rendah, yakni tidak lebih dari 3 ton ha' ${ }^{-1}$ (Helmi, 2015; Suparwoto, 2019). Masyarakat memiliki preferensi terhadap varietas padi lokal didasarkan pertimbangan kemampuannya yang dapat beradaptasi baik pada ekosistem rawa. Dalam kondisi demikian, program pengembangan varietas padi berdaya hasil tinggi dan adaptif pada ekosistem rawa dengan memanfaatkan daya adaptasi yang dimiliki oleh varietasvarietas padi rawa lokal merupakan alternatif yang sangat relevan untuk menunjang peningkatan produksi padi pada lahan rawa. Galur merupakan materi genetik yang dihasilkan melalui proses seleksi dalam program pengembangan varietas yang memerlukan sejumlah pengujian sebelum dapat dilepas sebagai varietas. Penelitian ini dilaksanakan dengan tujuan untuk mengevaluasi penampilan agronomis dan produktivitas dari galur-galur padi rawa yang dihasilkan dari persilangan antara padi rawa lokal Bengkulu dengan varietas unggul nasional.

\section{BAHAN DAN METODE}

\section{Bahan Tanam dan Kondisi Lahan}

Bahan tanaman yang digunakan terdiri atas 12 genotipe padi rawa, yaitu 10 galur (UBPR 1, UBPR 2, UBPR 3, UBPR 4, UBPR 6, UBPR 7, UBPR 8, UBPR 9, UBPR 10, dan UBPR 11) dan 2 varietas pembanding (Inpara 4 dan Inpara 5). Galur-galur tersebut adalah generasi F7 hasil seleksi dari persilangan yang melibatkan varietas-varietas padi rawa lokal di Bengkulu (Tabel 1). Hanafi putih, Batubara, Tigotigo, Harum Curup, dan Lubuk Durian adalah varietasvarietas padi rawa lokal Bengkulu, sedangkan Sidenuk, Diahsuci, dan Bestari adalah varietas unggul nasional yang dirilis oleh Badan Tenaga Nuklir Nasional (BATAN). Penelitian dilaksanakan pada lahan rawa lebak dangkal (5 m dpl) di lingkungan Fakultas Pertanian Universitas Bengkulu pada bulan Juni hingga Oktober 2018. Lahan memiliki permukaan gambut dengan ketebalan berkisar antara $30 \mathrm{~cm}$ dan $50 \mathrm{~cm}$ dan $\mathrm{pH}$ tanah berkisar antara 4.5-5.2.

\section{Rancangan Percobaan}

Rancangan acak kelompok lengkap dengan tiga ulangan digunakan untuk mengalokasikan galur-galur dan varietas pembanding pada petak-petak percobaan berukuran $2.5 \mathrm{~m}$ x $2.5 \mathrm{~m}$. Jarak antar kelompok adalah $1 \mathrm{~m}$ dan jarak antar petak dalam tiap kelompok adalah $0.5 \mathrm{~m}$.

\section{Pengelolaan Tanaman}

Bibit dari masing-masing genotipe dipindah-tanamkan ke lahan percobaan ketika berumur 21 hari setelah sebar benih. Penanaman pada tiap petak percobaan dilakukan secara manual dengan jarak tanam $25 \mathrm{~cm} \mathrm{x} 25 \mathrm{~cm}$. Pemupukan pada tanaman utama diberikan dengan dosis pupuk Urea (75 kg ha $\left.{ }^{-1}\right)$, SP-36 (100 kg ha-1) dan KCl (100 $\mathrm{kg} \mathrm{ha}^{-1}$ ), digunakan sebagai pupuk dasar dan diaplikasikan

Tabel 1. Galur-galur yang dievaluasi beserta tetuanya

\begin{tabular}{lll}
\hline Galur & Tetua betina & Tetua jantan \\
\hline UBPR 1 & Hanafi putih & Sidenuk \\
UBPR 2 & Batubara & Harum Curup \\
UBPR 3 & Tigo-tigo & Harum Curup \\
UBPR 4 & Tigo-tigo & Sidenuk \\
UBPR 6 & Diahsuci & Lubuk Durian \\
UBPR 7 & Harum Curup & Sidenuk \\
UBPR 8 & Sidenuk & Lubuk Durian \\
UBPR 9 & Lubuk Durian & Hanafi putih \\
UBPR 10 & Tigo-tigo & Bestari \\
UBPR 11 & Harum Curup & Bestari \\
\hline
\end{tabular}


satu hari sebelum penanaman. Pupuk tambahan berupa urea (75 $\left.\mathrm{kg} \mathrm{ha}^{-1}\right)$ diberikan ketika tanaman memasuki fase primordia atau pada saat tanaman berumur 56 hari setelah sebar benih.

\section{Pengumpulan dan Analisis Data}

Data karakter agronomis dan hasil dikumpulkan melalui pengamatan tinggi tanaman, jumlah anakan total per rumpun, jumlah anakan produktif per rumpun, umur berbunga, umur panen, panjang malai, jumlah gabah per malai, persentase gabah bernas per malai, bobot 100 gabah, bobot gabah per rumpun, bobot gabah per petak, dan bobot gabah per hektar. Selain bobot gabah per petak, pengamatan dilakukan pada 10 tanaman sampel dengan mengacu pada Standard Evaluation System for Rice (IRRI, 2013). Analisis ragam untuk menguji kebermaknaan keragaman antar genotipe dilakukan dengan menggunakan software SAS V9.4. Analisis klaster Scott-Knott untuk pengelompokan genotipe dilakukan dengan menggunakan software DSAASTAT.

\section{HASIL DAN PEMBAHASAN}

\section{Penampilan Agronomis}

Hasil analisis varian untuk karakter agronomis menunjukkan keragaman yang nyata antar genotipe. Ratarata penampilan pertumbuhan dan perkembangan tanaman dari 12 genotipe yang dievaluasi disajikan pada Tabel 2. Berdasarkan tinggi tanamannya, UBPR 1, UBPR 3, UBPR 4, dan UBPR 10 dapat dikategorikan sebagai galur yang memiliki postur cukup tinggi, sedangkan UBPR 2, UBPR 6, UBPR 7, UBPR 8, UBPR 9, dan UBPR 11 dapat dikategorikan sebagai galur yang memiliki postur pendek dan setara dengan postur varietas pembanding. Postur tanaman yang tinggi umumnya kurang diminati karena rentan terhadap kerebahan, sebaliknya bila postur tanaman terlalu pendek, tanaman akan rentan terhadap rendaman yang sering terjadi di lahan rawa lebak. Jika tinggi tanaman dari genotipe-genotipe tersebut dikelompokkan sesuai dengan kriteria IRRI (2013), maka hanya UBPR 3 yang dapat dikategorikan memiliki postur tinggi $(\geq 130 \mathrm{~cm})$, sedangkan UBPR 1 dan UBPR 10 serta UBPR 4 dikategorikan memiliki postur sedang $(110 \mathrm{~cm}-130 \mathrm{~cm})$. Enam galur lainnya dan varietas pembanding dikategorikan memiliki postur pendek $(<110 \mathrm{~cm})$.

Jumlah anakan total per rumpun maksimum dihasilkan oleh UBPR 1 dan diikuti oleh UBPR 4. Jumlah tersebut lebih banyak dibanding galur-galur lain maupun varietas pembanding yang menghasilkan jumlah anakan per rumpun yang setara. IRRI (2013) mengelompokkan jumlah anakan total per rumpun menjadi 5 kategori, yaitu sangat sedikit ( $<5$ batang), sedikit (5-9 batang), sedang (10-19 batang), banyak (20-25 batang) dan sangat banyak ( $>25$ batang). Dengan kategori tersebut maka jumlah anakan total per rumpun yang dihasilkan oleh UBPR 1 dan UBPR 4 tergolong sangat banyak, tujuh galur lainnya dan varietas pembanding tergolong banyak, dan hanya UBPR 7 yang tergolong sedang (Tabel 2). Beberapa survei menunjukkan bahwa jumlah anakan total per rumpun merupakan karakter agronomis penting bagi petani dalam menentukan preferensi terhadap suatu varietas (Wulandari dan Sudrajat, 2017; Darsani dan Hairani, 2020).

Berdasarkan umur berbunga, genotipe-genotipe yang dievaluasi dapat dibedakan menjadi lima kelompok. Umur berbunga paling lambat ditunjukkan oleh UBPR 10, yaitu 113.3 HSS (hari setelah semai), yang diikuti oleh UBPR 3, UBPR 1, dan UBPR 4 yang masing-masing juga memiliki umur berbunga $>100$ HSS. UBPR 6 merupakan

Tabel 2. Rata-rata penampilan pertumbuhan dan perkembangan dari 12 genotipe padi rawa pada lahan lebak

\begin{tabular}{lcccc}
\hline Genotipe & $\begin{array}{c}\text { Tinggi tanaman } \\
(\mathrm{cm})\end{array}$ & $\begin{array}{c}\text { Jumlah anakan total } \\
\text { per rumpun }\end{array}$ & $\begin{array}{c}\text { Umur berbunga } \\
(\text { HSS })\end{array}$ & $\begin{array}{c}\text { Umur panen } \\
(\text { HSS })\end{array}$ \\
\hline UBPR 1 & $126.23 \mathrm{a}$ & $35.6 \mathrm{a}$ & $102.0 \mathrm{~b}$ & $141.0 \mathrm{~b}$ \\
UBPR 2 & $91.13 \mathrm{~b}$ & $20.9 \mathrm{~b}$ & $87.0 \mathrm{~d}$ & $115.7 \mathrm{~d}$ \\
UBPR 3 & $139.37 \mathrm{a}$ & $20.0 \mathrm{~b}$ & $103.0 \mathrm{~b}$ & $138.0 \mathrm{~b}$ \\
UBPR 4 & $116.65 \mathrm{a}$ & $31.0 \mathrm{a}$ & $101.0 \mathrm{~b}$ & $134.0 \mathrm{~b}$ \\
UBPR 6 & $98.47 \mathrm{~b}$ & $20.7 \mathrm{~b}$ & $77.7 \mathrm{e}$ & $110.0 \mathrm{~d}$ \\
UBPR 7 & $98.90 \mathrm{~b}$ & $19.0 \mathrm{~b}$ & $91.0 \mathrm{~d}$ & $120.0 \mathrm{c}$ \\
UBPR 8 & $87.75 \mathrm{~b}$ & $21.0 \mathrm{~b}$ & $85.0 \mathrm{~d}$ & $114.5 \mathrm{~d}$ \\
UBPR 9 & $82.80 \mathrm{~b}$ & $21.7 \mathrm{~b}$ & $83.7 \mathrm{~d}$ & $114.7 \mathrm{~d}$ \\
UBPR 10 & $125.40 \mathrm{a}$ & $19.6 \mathrm{~b}$ & $113.3 \mathrm{a}$ & $144.7 \mathrm{a}$ \\
UBPR 11 & $98.27 \mathrm{~b}$ & $23.7 \mathrm{~b}$ & $87.7 \mathrm{~d}$ & $122.7 \mathrm{c}$ \\
Inpara 4 & $90.53 \mathrm{~b}$ & $22.7 \mathrm{~b}$ & $85.7 \mathrm{~d}$ & $118.7 \mathrm{c}$ \\
Inpara 5 & $102.38 \mathrm{~b}$ & $23.5 \mathrm{~b}$ & $96.5 \mathrm{c}$ & $124.0 \mathrm{c}$ \\
\hline
\end{tabular}

Keterangan: Angka yang diikuti huruf yang sama pada kolom yang sama menujukkan kelompok yang sama berdasarkan analisis klaster Scott-Knott pada taraf $\alpha=5 \%$. HSS $=$ Hari setelah semai 
genotipe yang memiliki umur berbunga paling cepat $(<$ $80 \mathrm{HSS}$ ), sedangkan genotipe lainnya termasuk 3 varietas pembanding memiliki umur berbunga antara 84 HSS dan 97 HSS (Tabel 2). Pola pengelompokkan serupa juga berlaku untuk umur panen. Dengan merujuk klasifikasi umur panen BB Padi (2016), UBPR 10, UBPR 3, UBPR 1, dan UBPR 4 dikategorikan sebagai galur yang termasuk memiliki umur sedang (125 HSS-150 HSS), sedangkan genotipe lainnya termasuk berumur genjah (105 HSS-124 HSS). Padi rawa umumnya dibudidayakan pada akhir musim hujan sehingga petani padi rawa menyukai varietas berumur genjah guna menghindari kekurangan air pada fase akhir pertumbuhan tanaman (Darsani dan Hairani, 2020; Rumanti et al., 2020).

Tabel 3 menyajikan rata-rata penampilan komponen hasil dari tiap genotipe yang dievaluasi. Jumlah anakan produktif per rumpun kedua belas genotipe dapat dibedakan menjadi dua kelompok, sebagaimana jumlah anakan total per rumpun. UBPR 1 dan UBPR 4 merupakan galur yamg dapat menghasilkan anakan produktif per rumpun $>27$ batang, sedangkan galur-galur lainnya dan varietas pembanding menghasilkan anakan produktif per rumpun yang lebih rendah ( $<22$ batang). Jika dipersentasekan jumlah anakan produktif per rumpun dari jumlah anakan total per rumpun pada Tabel 2, maka rata-rata persentase anakan produktif per rumpun dari total anakan per rumpun juga termasuk tinggi, yaitu $81.09 \%$. Persentase tertinggi ditunjukkan oleh UBPR $1(92.13 \%)$ dan persentase terendah ditunjukkan oleh UBPR 9 (69.12\%), sedangkan Inpara 4 dan Inpara 5 masing-masing memiliki persentase $80.18 \%$ dan $86.21 \%$.

Panjang malai yang dimiliki oleh UBPR 3, UBPR 6, UBPR 7, UBPR 8, UBPR 9, dan UBPR 10 dengan kisaran antara $22.43 \mathrm{~cm}-24.20 \mathrm{~cm}$. UBPR 2 memiliki panjang malai yang setara dengan varietas pembanding dengan kisaran antara $20.3 \mathrm{~cm}-21.2 \mathrm{~cm}$, sedangkan UBPR1, UBPR 4 dan UBPR 11 memiliki panjang malai yang lebih pendek dari varietas pembanding, dengan kisaran antara $18.70 \mathrm{~cm}$ dan
$19.6 \mathrm{~cm}$. Rembang et al. (2018) mengelompokkan panjang malai menjadi tiga kategori, yakni panjang $(>30 \mathrm{~cm})$, sedang (20-30 cm), dan pendek ( $\leq 20 \mathrm{~cm})$. Dengan mengacu pada pengelolompokkan tersebut, maka sebagian besar genotipe dapat dikategorikan memiliki panjang malai sedang, kecuali UBPR1, UBPR 4 dan UBPR 11 dikategorikan memiliki panjang malai pendek.

Panjang malai ternyata tidak selalu berbanding lurus dengan jumlah gabah yang dihasilkan tiap malainya. UBPR 2, UBPR 3, UBPR 7, UBPR 8, dan UBPR 10 serta varietas pembanding yang memiliki panjang malai kategori sedang dapat menghasilkan > 100 gabah, namun UBPR 6 dan UBPR 9 yang juga memiliki panjang malai kategori sedang hanya menghasilkan gabah $<100$. Sebaliknya, UBPR 1, UBPR 4, dan UBPR 11 yang memiliki panjang malai dengan kategori pendek dapat menghasilkan $>100$ gabah. Jumlah gabah per malai dengan kisaran yang setara juga dilaporkan oleh Kustianto (2009) dan Rumanti et al. (2020).

Secara umum, persentase gabah bernas yang dihasilkan tiap malai termasuk tinggi, yaitu $>75 \%$, dan lebih tinggi dari beberapa hasil penelitian padi rawa (Lestari dan Kasim, 2014; Helmi 2015). Dari 10 galur yang divaluasi, terdapat 5 galur (UBPR 3, UBPR 4, UBPR 9, UBPR 10, dan UBPR 11) yang menghasilkan persentase gabah bernas setara dengan varietas pembanding $(>85 \%)$ atau setara dengan varietas-varietas unggul padi rawa lainnya (Guwat et al., 2018; Jumakir dan Endrizal, 2017).). Galur lainnya, yaitu UBPR 3, UBPR 4, UBPR 9, UBPR 10, dan UBPR 11 menghasilkan persentase gabah bernas yang lebih rendah, namun masih lebih tinggi dari 75\% (Tabel 3).

Bobot 1,000 gabah merupakan cerminan ukuran gabah dan berdasarkan karakter tersebut, UBPR 1 merupakan galur yang menghasilkan ukuran gabah terbesar dan diikuti oleh UBPR 4 dan UBPR 3 (Tabel 3). Ukuran gabah yang dihasilkan dari 7 galur lainnya umumnya setara dengan ukuran gabah varietas pembanding.

Tabel 3. Rata-rata penampilan komponen hasil dari 12 genotipe padi rawa pada lahan lebak

\begin{tabular}{|c|c|c|c|c|c|}
\hline Genotipe & $\begin{array}{l}\text { Jumlah anakan } \\
\text { produktif per rumpun }\end{array}$ & $\begin{array}{l}\text { Panjang malai } \\
(\mathrm{cm})\end{array}$ & $\begin{array}{l}\text { Jumlah gabah } \\
\text { per malai }\end{array}$ & $\begin{array}{l}\text { Persentase gabah } \\
\text { bernas per malai }\end{array}$ & $\begin{array}{c}\text { Bobot 1,000 gabah } \\
(\mathrm{g})\end{array}$ \\
\hline UBPR 1 & $32.8 \mathrm{a}$ & $19.6 c$ & $114.0 \mathrm{c}$ & $82.9 a$ & $30.7 \mathrm{a}$ \\
\hline UBPR 2 & $14.8 b$ & $20.8 b$ & $114.7 \mathrm{c}$ & $79.0 \mathrm{~b}$ & $23.7 \mathrm{c}$ \\
\hline UBPR 3 & $18.1 b$ & $22.4 \mathrm{a}$ & $137.0 \mathrm{a}$ & $86.3 \mathrm{a}$ & $26.3 b$ \\
\hline UBPR 4 & $27.6 \mathrm{a}$ & $18.7 \mathrm{c}$ & $106.5 \mathrm{c}$ & $86.6 \mathrm{a}$ & $27.0 \mathrm{~b}$ \\
\hline UBPR 6 & $14.4 \mathrm{~b}$ & $22.9 \mathrm{a}$ & $97.3 d$ & $79.7 b$ & $20.7 \mathrm{c}$ \\
\hline UBPR 7 & $13.2 b$ & $24.1 \mathrm{a}$ & $124.7 \mathrm{~b}$ & $80.7 b$ & $23.0 \mathrm{c}$ \\
\hline UBPR 8 & $16.6 \mathrm{~b}$ & $24.2 \mathrm{a}$ & $116.0 \mathrm{c}$ & $75.5 b$ & $25.0 \mathrm{c}$ \\
\hline UBPR 9 & $15.0 \mathrm{~b}$ & $23.5 \mathrm{a}$ & $98.0 \mathrm{~d}$ & $86.3 \mathrm{a}$ & $24.7 \mathrm{c}$ \\
\hline UBPR 10 & $17.0 \mathrm{~b}$ & $23.6 \mathrm{a}$ & $141.7 \mathrm{a}$ & $84.6 \mathrm{a}$ & $23.0 \mathrm{c}$ \\
\hline UBPR 11 & $21.4 b$ & $18.8 \mathrm{c}$ & $108.3 \mathrm{c}$ & $87.2 \mathrm{a}$ & $22.3 \mathrm{c}$ \\
\hline Inpara 4 & $18.2 b$ & $21.2 b$ & $103.2 d$ & $86.7 \mathrm{a}$ & $23.5 \mathrm{c}$ \\
\hline Inpara 5 & $20.3 b$ & $20.3 b$ & $112.1 \mathrm{c}$ & $85.0 \mathrm{a}$ & $2.35 \mathrm{c}$ \\
\hline
\end{tabular}

Keterangan: Angka yang diikuti huruf yang sama pada kolom yang sama menujukkan kelompok yang sama berdasarkan analisis klaster Scott-Knott pada taraf $\alpha=5 \%$ 


\section{Produktivitas}

Hasil analisis varian juga menunjukkan keragaman yang nyata antar genotipe untuk karakter hasil tanaman. Pada Tabel 4 disajikan rata-rata penampilan bobot gabah per rumpun dan bobot gabah per hektar dengan pola pengelompokkan yang sama. UBPR 1, UBPR 2, UBPR 3, UBPR 7, UBPR 8, dan UBPR 10 menunjukkan hasil gabah lebih tinggi dibanding varietas pembanding, sedangkan UBPR 4, UBPR 6, UBPR 9, dan UBPR 11 menunjukkan hasil gabah yang setara dengan varietas pembanding.

Tabel 4. Rata-rata bobot gabah per rumpun dan per petak dari 12 genotipe padi rawa pada lahan lebak

\begin{tabular}{ccc}
\hline Genotipe & $\begin{array}{c}\text { Bobot gabah } \\
\text { per }\end{array}$ & $\begin{array}{c}\text { rumpun }(\mathrm{g}) \\
\text { per hektar (ton) }\end{array}$ \\
\hline UBPR 1 & $44.58 \mathrm{a}$ & $5.69 \mathrm{a}$ \\
UBPR 2 & $33.70 \mathrm{a}$ & $5.69 \mathrm{a}$ \\
UBPR 3 & $34.35 \mathrm{a}$ & $6.62 \mathrm{a}$ \\
UBPR 4 & $28.80 \mathrm{~b}$ & $5.42 \mathrm{~b}$ \\
UBPR 6 & $19.56 \mathrm{~b}$ & $4.93 \mathrm{~b}$ \\
UBPR 7 & $40.57 \mathrm{a}$ & $6.49 \mathrm{a}$ \\
UBPR 8 & $39.84 \mathrm{a}$ & $6.31 \mathrm{a}$ \\
UBPR 9 & $29.22 \mathrm{~b}$ & $4.89 \mathrm{~b}$ \\
UBPR 10 & $36.84 \mathrm{a}$ & $6.00 \mathrm{a}$ \\
UBPR 11 & $20.49 \mathrm{~b}$ & $4.53 \mathrm{~b}$ \\
Inpara 4 & $24.86 \mathrm{~b}$ & $4.71 \mathrm{~b}$ \\
Inpara 5 & $26.64 \mathrm{~b}$ & $5.07 \mathrm{~b}$ \\
\hline
\end{tabular}

Keterangan: Angka yang diikuti huruf yang sama pada kolom yang sama menujukkan kelompok yang sama berdasarkan analisis klaster Scott-Knott pada taraf $\alpha=5 \%$

\section{KESIMPULAN}

Galur-galur padi rawa dan varietas pembanding yang dievaluasi menunjukkan penampilan agronomis dan produktivitas yang beragam ketika dibudidayakan pada agroekosistem lebak dangkal. UBPR 4, UBPR 9, dan UBPR 11 memiliki penampilan agronomis dan produktivitas yang setara dengan kedua varietas pembanding (Inpara 4 dan Inpara 5). UBPR 2, UBPR 7, dan UBPR 8 memiliki penampilan agronomis yang setara dengan kedua varietas pembanding, namun produktivitasnya lebih tinggi. UBPR 1, UBPR 3, UBPR 4, dan UBPR 10 memiliki postur tanaman yang relatif tinggi dan umur lebih dalam dibandingkan dengan dua varietas pembanding, namun produktivitasnya lebih tinggi. Namun demikian, pengujian lanjutan pada berbagai tipologi rawa masih diperlukan untuk mengevaluasi adaptabilitas dan stabilitas hasilnya sebelum galur-galur tersebut diusulkan dalam pelepasan varietas.

\section{UCAPAN TERIMA KASIH}

Ucapan terima kasih kami sampaikan kepada Lembaga Penelitian dan Pengabdian Kepada Masyarakat Universitas Bengkulu yang telah membiayai pelaksanaan penelitian melalui skema Penelitian Terapan Unggulan Perguruan Tinggi (PTUPT) tahun 2018 dengan nomor kontrak 2356/ UN30.15/LT/2018.

\section{DAFTAR PUSTAKA}

[BB Padi] Balai Besar Padi. 2016. Klasifikasi umur padi. http://bbpadi.litbang.pertanian.go.id [18 Agustus 2019].

Darsani, Y.R., A. Hairani. 2020. Preferensi petani terhadap keragaan padi varietas unggul baru di rawa lebak tengahan. J. Soc. Econ. Agric. 9:22-32.

Djafar, Z.R. 2019. The potential of swamp land to support national food security. hal. 45-52. Dalam S. Herlinda, H. Natawidjaja, B. Lakitan, D. Asmono, I. Effendi, W. Budiharto, Suwandi, S. Sudirman, M. I. Syafutri, Puspitahati, Tanbiyaskur, A.D. Sasanti (Eds.), Prosiding Seminar Nasional Lahan Suboptimal. Palembang 4-5 September 2019.

Gazali, A., F. Fathurrahman. 2019. Tinjauan aspek tanah dalam pengelolaan daerah rawa pasang surut di Kalimantan Selatan. Specta J. Technol. 3:13-24.

Guwat, S., W. Waluyo, P. Priatna. 2018. Produksi dan usahatani padi varietas unggul baru di lahan rawa lebak Kabupaten Banyuasin Sumatera Selatan. J. Penelitian Pertanian Terapan 17:176-181.

Hairmansis, A. 2020. Pengembangan varietas unggul padi untuk lahan terdampak salinitas. J. Pangan 29:161170.

Helmi, H. 2015. Peningkatan produktivitas padi lahan rawa lebak melalui penggunaan varietas unggul padi rawa. J. Pert. Tropik 2:78-92.

[IRRI] International Rice Research Institute. 2013. Standard Evaluation System for Rice, 5th Edition. International Rice Research Institute, P.O. Box 933, 1099 Manila, Philippines.

Jumakir, Endrizal. 2017. Keragaan dan produktivitas beberapa varitas unggul baru inpara di lahan rawa pasang surut tipologi lahan sulfat masam di Provinsi Jambi. J. Pangan 26:107-116.

Kustianto, B. 2009. Produktivitas galur harapan padi di lahan pasang surut dan rawa lebak. J. Pen. Pert. Tan. Pangan 28:34-38. 
Lestari, R.H., A. Kasim. 2014. Pengkajian varietas padi unggul baru pada lahan rawa pasang surut di Kabupaten Marauke. Informatika Pertanian 23:5964.

Mulyani, A., D. Kuncoro, D. Nursyamsi, F. Agus. 2016. Analisis konversi lahan sawah: penggunaan data spasial resolusi tinggi memperlihatkan laju konversi yang mengkhawatirkan. J. Tanah Iklim 40:121-133.

Rembang, J.H., A.W. Rauf, J.O. Sondakh. 2018. Karakter morfologi padi sawah lokal di lahan petani Sulawesi Utara. Bul. Plasma Nutfah 24:1-8.

Rumanti, I.A., Koesrini, H. Sosiawan, Y. Rina. 2020. Uji adaptasi dan seleksi varietas partisipatif terhadap galur-galur padi toleran rendaman dan kekeringan di lahan rawa lebak. J. Agron. Indonesia 48:118-126.

Subagio, H. 2019. Evaluasi penerapan teknologi intensifikasi budidaya padi di lahan rawa pasang surut. J. Pangan 28:95-108.

Sudana, W. 2017. Potensi dan prospek lahan rawa sebagai sumber produksi pertanian. Analisis Kebijakan Pertanian 3:141-151.
Suparwoto, S. 2019. Produksi dan pendapatan usahatani padi di lahan rawa lebak Kabupaten Ogan Komering Ilir Sumatera Selatan. J. Sosial Ekonomi Pertanian 13:51-60.

Suriadikarta, D.A., M.T, Sutriadi. 2007. Jenis-jenis lahan berpotensi untuk pengembangan pertanian di lahan rawa. J. Litbang. Pertanian 26:115-122.

Takim, M.H. 2018. Perlindungan hukum lahan pertanian pangan berkelanjutan (PLP2B) di Kabupaten Gresik terhadap ijin usaha dan industri. Airlangga Dev. J. 2:57-71.

Waluyo, W., S. Djamhari. 2011. Sifat kimia tanah dan kesesuaian lahan pada masing-masing tipologi lahan rawa lebak untuk budidaya tanaman padi, kasus di Desa Tanjung Elai, Ogan Komering Ilir. J. Sainsteknol. Indonesia 13:13-23.

Wulandari, N.S., S. Sudrajat. 2017. Preferensi petani dalam penentuan varietas benih padi di Desa Pablengan Kecamatan Matesih Kabupaten Karanganyar. J. Bumi Indonesia 6:1-9. 